\title{
Accelerating achievement of the sustainable development goals
}

A game changer in global health

\author{
Ashish Jha professor ${ }^{1}$, Ilona Kickbusch director, Global Health Programme ${ }^{2}$, Peter Taylor programme \\ manager $^{3}$, Kamran Abbasi international editor ${ }^{4}$, on behalf of the SDGs working group
}

${ }^{1}$ Harvard Global Health Institute, Cambridge, MA 02138, USA; ${ }^{2}$ Graduate Institute, Geneva, Switzerland; ${ }^{3}$ Think Tank Initiative, International Development Research Centre, Ottawa, Ontario, Canada; ${ }^{4}$ The BMJ, London WC1H 9JR, UK

In September 2015, nearly 200 nations adopted the 17 sustainable development goals (SDGs) as a transformative, universal framework to address three interwoven dimensions of our global existence-people, planet, and prosperity. ${ }^{1}$ They are predicated on the notion that sustainability is not just an aspiration but a necessity. However, by substantially expanding on the scope and targets of their predecessors (the millennium development goals), the SDGs have set a high bar. To achieve them, we will need collective action to create new knowledge, share and broker knowledge, and implement insights through working with many sectors and diverse global health policy stakeholders. With this in mind, 60 global health policy think tanks from around the world met in Geneva in November 2015 to explore the role that think tanks and academic institutions have in implementing the SDGs.

\section{What will it take to achieve the SDGs related to health?}

Although only SDG3 focuses primarily on health, many other development goals, including those that relate to the environment, nutrition, hunger, sustainable production and consumption, agriculture, and education, also have a big effect on health. To achieve progress on human health, countries will therefore need to commit to a broad agenda of sustainable development that acknowledges and exploits the links between different goals and targets. This provides an opportunity for systems thinking: applying an ecological perspective and implementing an ambitious agenda in which health is included in all government policies.

The most obvious challenge is ensuring the political will to identify and commit adequate financial resources..$^{2-4}$ But to ensure those commitments lead to better health, three important issues will need to be addressed: global knowledge sharing, capacity building, and innovation. Civil society agencies such as think tanks and academic institutions can be critical catalysts to accelerate the SDG agenda at all levels of governance.
Knowledge sharing - New knowledge about determinants of health, responses to diseases, mitigation of environmental problems, and successful policies and programme implementation is generated rapidly. Yet, knowledge often diffuses too slowly. For example, even affordable, lifesaving therapies can take over a decade to become widely used. ${ }^{5}$ Ensuring that knowledge is treated as a global public good and disseminated quickly, effectively, and widely should be a priority.

Capacity building-Even with greater sharing of knowledge, substantial challenges to implementing the SDGs remain. ${ }^{6}$ Many countries lack the technical capacity to implement programmes despite knowledge of what to do. Governments will need to enter into partnerships with other key actors to develop and implement policy and track the progress along the way. ${ }^{7}$ Reliable data to ensure political accountability will be critical.

Innovation-Even with existing knowledge and technical expertise, many countries will find it difficult to meet SDG targets without innovation and adaptation to their specific needs. Challenges include reconceptualising how universal health coverage can work in resource limited settings; exploring how to best create intersectoral policies to tackle the causes of non-communicable diseases; and harnessing the power of technology to ensure better community accountability. There is no limit to the number of innovations that could help nations accelerate implementation of SDGs.

\section{Global health policy stakeholders and the role of think tanks and academic institutions}

The meeting in Geneva concluded that global health policy think tanks and academic institutions have a critical role in filling some of the needs outlined above, especially ensuring effective sharing of knowledge, technical assistance to tackle 
implementation challenges, and the creation of innovative strategies to achieve better health.

Think tanks and academic institutions have a natural domain of expertise: knowledge. They help generate, translate, and disseminate knowledge. Thus, they have a responsibility to help accelerate the SDG process through a focus on the political and policy dimensions: engaging in broader policy development, measuring the outcomes of policies and identifying determinants of success, acting as a knowledge broker, and giving a voice to civil society. Their work can provide direct input to high level processes, support a more effective implementation of the goals and actions, and contribute to ensuring the political accountability needed to achieve SDGs.

Finally, these bodies can catalyse innovation in global and national healthcare systems. Some think tanks and academic institutions will have a central role in creating the innovations while others will focus more on measurement, evaluation, and dissemination. New ideas and solutions to longstanding problems can take years to filter through society and people, and the poorest and most disenfranchised are often the last to benefit. Think tanks and relevant academic institutions can help bridge this gap and ensure that innovations get to those who need them more quickly.

SDGs have the potential to be a game changer in global health - a platform and mechanism to greatly improve the health and wellbeing of the world's population. But if the millennium development goals and other global goals are any indication, initial progress will be slow. The cost of this slow action is likely to be measurable in lives lost. Achieving the SDGs will not be easy. Think tanks and academic institutions can catalyse action by beginning to address the "North-South" divide that often plagues these discussions by enabling more "South-South" partnerships and by coming together beyond such divides to take the agenda forward. They can ensure that the best ideas are disseminated widely, no matter where they originate. And by holding governments and multilateral entities accountable, they can contribute to the voice of civil society.

The Graduate Institute, the International Development Research Centre, and The BMJ, in collaboration with other institutions committed to improvements in global public health, are launching a new initiative to accelerate achievement of the SDGs. Among other activities, we will publish a series of articles on this theme, and we welcome relevant original research and analyses for consideration. We are at a critical and exciting moment in global health. Broader trends in globalisation have created both tensions and opportunities. SDGs represent a key platform to capture the energy and goodwill that can drive real change. We believe that global health policy think tanks and academic institutions, by serving as honest brokers of knowledge and as a voice of society, can catalyse action in ways that will ensure that collectively we use this moment to improve the health of the world's population.

Competing interests: We have read and understood BMJ policy on declaration of interests and have no relevant interests to declare.

The SDGs working group is a collaboration of global institutions working towards accelerating achievement of the SDGs. The members are Paulo Buss, Abby Campbell, Ashish Jha, Yasushi Katsuma, llona Kickbusch, Francis Omaswa, Miriam Maria Sangiorgio, Peter Taylor, Michaela Told, Goran Tomson, and Kamran Abbasi.

Provenance and peer review: Commissioned; not externally peer reviewed.

1 United Nations. Transforming our world: the 2030 agenda for sustainable development. 2015. https://sustainabledevelopment.un.org/content/documents/21252030\%20Agenda\% 20for\%20Sustainable\%20Development\%20web.pdf.

2 From billions to trillions: MDB contributions to financing for development. 2015. www. worldbank.org/mdgs/documents/FfD-MDB-Contributions-July-10-2015.pdf.

3 Yamey G, Shretta R, Newton Binka F. The 2030 sustainable development goal for health BMJ 2014;349:g5295.

4 Schmidt-Traub G, Sachs, JD. Financing sustainable development: implementing the SDGs through effective investment strategies and partnerships. 2015. http://unsdsn.org/ wp-content/uploads/2015/04/150619-SDSN-Financing-Sustainable-Development-PaperFINAL-02.pdf.

5 World Health Organization. The stop TB strategy: building on and enhancing DOTS to meet the TB-related millennium development goals. 2006. www.who.int/tb/publications/ 2006/who_htm_tb_2006_368.pdf.

6 Sarvajayakesavalu S. Addressing challenges of developing countries in implementing five priorities for sustainable development goals. Ecosystem Health Sustainability 2015;1:24.

7 Lubchenco J, Barner AK, Cerny-Chipman EB, Reimer JN. Sustainability rooted in science. Nature Geoscience 2015;8:741-5.

Cite this as: BMJ 2016;352:i409 